Fourth International Conference on Sustainable Construction Materials and Technologies http://www.claisse.info/Proceedings.htm

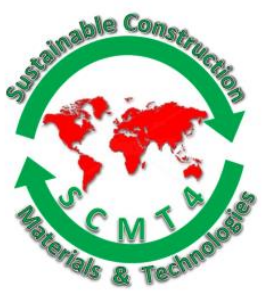

SCMT4

Las Vegas, USA, August 7-11, 2016

\title{
Effectiveness of Recycled Nylon Fibers in Mortar Comparing with Recycled PET and PVA Fibers
}

\author{
Shanya Orasutthikul ${ }^{1 \mathrm{a}}$, Hiroshi Yokota ${ }^{1 \mathrm{~b}}$, Katsufumi Hashimoto ${ }^{1 \mathrm{c}}$, and Daiki Unno ${ }^{1 \mathrm{~d}}$ \\ ${ }^{1}$ Graduate School of Engineering, Hokkaido University, Kita 13, Nishi 8, Kita-Ku, Sapporo-shi, Hokkaido \\ 060-8628, Japan. ${ }^{1 a}$ Email: <orasutthikul.shanya@gmail.com>, ${ }^{1 b}$ Email:<yokota@eng.hokudai.ac.jp>, \\ ${ }^{1 c}$ Email: $\left\langle\right.$ hashimoto.k@eng.hokudai.ac.jp>, ${ }^{1 d}$ Email: $\langle$ daiki-unno-0203@eis.hokudai.ac.jp>.
}

\begin{abstract}
In this study, the authors focused on the potential and efficiency of recycled nylon fibers obtained from waste fishing nets as tensile reinforcement of mortar, and discussed comparisons with the experimental results of recycled PET and PVA fibers. The recycled nylon fibers were obtained through manual cutting of waste fishing net at different lengths of $20 \mathrm{~mm}, 30 \mathrm{~mm}$ and $40 \mathrm{~mm}$, and mixed in mortar with the volumes of $1.0 \%, 1.5 \%$ and $2.0 \%$. It was observed that recycled nylon fibers significantly enhances the mechanical properties of mortar as well as post peak response and ductile behavior. The addition of recycled-nylon fibers improved modulus of rupture up to $41 \%$ more than recycled-PET and PVA fibers. However, compressive strength decreased as fiber fraction and aspect ratio increased. Additionally, the use of Rnylon fibers is beneficial in terms of environmental effect and economic products.
\end{abstract}

\section{INTRODUCTION}

Disposing of fishing nets has been a major concern in the seas and oceans environment. The number of abandoned fishing nets is remarkably increase in every year. Separating the nets for disposal is not practical because they become totally entangle. In addition, there were found about 705,000 tons of waste fishing nets in the North Pacific Ocean [Onegreenplanet.org]. The marine lives, especially turtles, seals and other marine mammals are directly affected; they can be entangled in these abandoned nets. In addition, they also disturb the marine food web by blocking sunlight to reach the plankton and algae below the surface of the oceans. This straight affect the animals that feed on algae and plankton. Nowadays, fishing nets are mostly made of nylon 6 which is not biodegradable. Although the storage of them does not cause any danger, it is very important to find the suitable ways for recycling them. Spadea et al. [2015] investigated the use of recycled nylon fiber to reinforce mortar. They observed that the toughness and ductility significantly improved from the addition of recycled reinforcing fibers to the mix-design.

During the past two decades, fiber reinforced mortars have been generally used to improve modulus of rupture, fracture toughness, impact resistance, and shrinkage controlling. Although the use of synthetic fibers, especially poly vinyl alcohol (PVA) and polypropylene fiber, was successful in significantly 
improving mechanical properties of fiber reinforced mortar. In recent years, many researchers have been focusing on using recycled materials [Pereira et al. 2011; Fraternali et al. 2013; Ozger et al. 2013]. They have not only concerned about mechanical properties but also environmental effects and economic products. There are lots of literature show that addition of recycled PET in to mortar can modify mechanical and chemical properties [Pereira et al. 2011; Fraternali et al. 2013]. Durability of fibers in alkali condition is very important to have high efficiency mortar composites. As evidences from the previous literature, recycled PET and recycled nylon fiber had excellent alkali resistance [Ochi et al. 2007; Spadea et al. 2015]. While tensile strength of PVA fibers after alkali test decreased to $56 \%$ of that before the test [Ochi et al. 2007].

In this study, the authors studied mechanical properties including compressive strength, flexural strength and toughness of different fibers containing mortar composites. Recycled fibers that are nylon and PET fibers, and virgin fiber that is PVA fiber, were investigated. The main objective of this study is to investigate the effectiveness of recycled (R)-nylon fiber from waste fishing nets in enhancing the mechanical properties of mortar, and compare with recycled (R)-PET and PVA fibers.

\section{METHODOLOGY}

The waste fishing nets in this experiment were collected by fishermen in Hokkaido, Japan. The nets were cut by hand at different lengths of $20 \mathrm{~mm}, 30 \mathrm{~mm}$ and $40 \mathrm{~mm}$. PVA and recycled PET fibers were supplied by Kuraray Company and Sango Company, respectively. All types of fibers are shown in figure 1 and the properties of all fibers are summarized in Table 1. Fiber contents in mortar were 1\%, 1.5\% and 2\% by volume.

After mixing cement and sand by small mixing machine, fibers were gently added to prevent forming fiber balls. Then, all dry components were mixed by hand in order to obtain a uniform distribution of fibers. Water gradually added, and used mechanical mixer to blend all mixture at low speed for 2 minutes until a homogeneous was achieved. The resulting mixture was then cast into $40 \mathrm{~mm}$ x $40 \mathrm{~mm}$ x $160 \mathrm{~mm}$ molds for flexural strength test and $50 \mathrm{~mm} \times 100 \mathrm{~mm}$ cylinders for compressive strength test. The specimens were covered with the plastic sheet for a period of 24 hours before they were demolded. After that they were cured in a water tank at $20^{\circ} \mathrm{C}$ for 28 days, the specimens were tested. As listed in Table 2, the mortar mixes vary due to the volume and aspect ratio of fibers. The unreinforced mortars are referred as UR, and the reinforced mortar specimens as "R-ny", "R-PET" and "PVA" fiber length - volume fraction, to represent recycled nylon fiber, recycled PET fiber and PVA fiber, respectively.

\section{EXPERIMENTAL RESULTS AND DISSCUSSIONS}

\section{Effect of fiber content and fiber length on compressive strength}

Cylinders were tested in compression in accordance with ASTM C 39. The compressive strength of all types of fibers with various fibers containing mortar are listed in Table 3. It can be obviously seen in figure 2 that increase in the length and amount of R-nylon fiber decrease the compressive strength. However, in previous literature they found that compressive strength decreased when fiber fraction increased but length decreased [Spadea et al. 2015]. In case of R-PET and PVA fibers, slightly reduction in compressive strength can be observed with the addition of fibers. Elastic moduli of mortars were reduced with the dosage of low modulus elasticity fiber were included, especially R-nylon fiber [Wang et al. 2000; $\mathrm{Hu}$ et al. 2013], and addition of fibers as though create voids in mortar specimens [Karahan 2011]. 

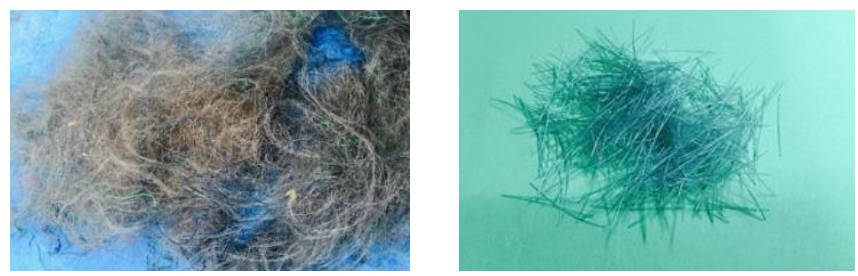

R-nylon fiber

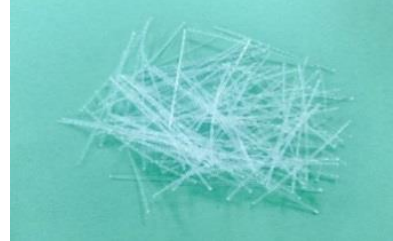

R-PET fiber

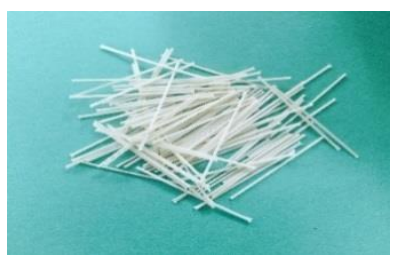

PVA30 fiber

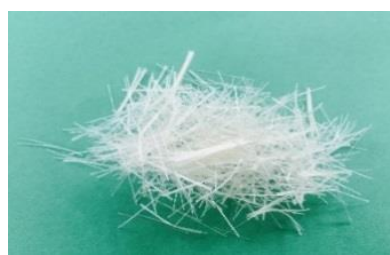

PVA18 fiber

Figure 1. Types of fibers

Table 1. The properties of fibers

\begin{tabular}{|c|c|c|c|c|}
\hline Types of fiber & $\begin{array}{c}\text { Diameter } \\
(\mu \mathrm{m})\end{array}$ & $\begin{array}{c}\text { Tensile strength } \\
(\mathrm{MPa})\end{array}$ & $\begin{array}{c}\text { Young's modulus } \\
(\mathrm{GPa})\end{array}$ & $\begin{array}{c}\text { Density } \\
\left(\mathrm{g} / \mathrm{cm}^{3}\right)\end{array}$ \\
\hline R-nylon fiber & 390 & 440 & 3.0 & 1.13 \\
\hline R-PET 30 & 700 & 450 & 20 & 1.32 \\
\hline R-PET 40 & 700 & 450 & 20 & 1.32 \\
\hline PVA 18 & 200 & 975 & 27 & 1.30 \\
\hline PVA 30 & 660 & 900 & 23 & 1.30 \\
\hline
\end{tabular}

\section{Effect of fiber content and fiber length on flexural strength}

After the specimens were cured for 28 days, three point bending tests were conducted according to ASTM C 1018. The results of three point bending test including the peak load and the first crack strength are presented in Table 3. It is evidenced that addition of R-nylon fibers into mortar improved the first crack strength up to $41 \%$. Spadea et al. [2015] observed that R-nylon fiber was very effective in increasing flexural strength (up to $35 \%$ ), especially, when the longer fibers were used. R-PET and PVA fibers improved first crack strength up to $24 \%$ and $32 \%$, respectively. The first crack strength can be determined as modulus of rupture as follows:

Where

$$
R=3 P L / 2 b d^{2}
$$

$R=$ modulus of rupture

$P=$ maximum applied load indicated by testing machine

$b=$ average width of the specimen at the fracture

$d=$ average depth of the specimen at the fracture

$L=$ span length 
Table 2. Types of specimen

\begin{tabular}{|c|c|c|c|c|c|}
\hline Types of specimen & $\begin{array}{c}\text { Fiber fraction } \\
\text { by volume }(\%)\end{array}$ & $\begin{array}{c}\text { Fiber length }(L) \\
(\mathrm{mm})\end{array}$ & $\begin{array}{c}\text { Diameter }(D) \\
(\mathrm{mm})\end{array}$ & $\begin{array}{c}\text { Aspect ratio } \\
(L / D)\end{array}$ & $\begin{array}{c}\text { Flow diameter } \\
(\mathrm{mm})\end{array}$ \\
\hline UR & 0 & - & - & - & 260 \\
\hline R-ny20-1 & 1 & 20 & 0.39 & 51 & 218 \\
\hline R-ny20-1.5 & 1.5 & 20 & 0.39 & 51 & 209 \\
\hline R-ny20-2 & 2 & 20 & 0.39 & 77 & 216 \\
\hline R-ny30-1 & 1 & 30 & 0.39 & 77 & 205 \\
\hline R-ny30-1.5 & 1.5 & 30 & 0.39 & 77 & 188 \\
\hline R-ny30-2 & 2 & 30 & 0.39 & 103 & 210 \\
\hline R-ny40-1 & 1 & 40 & 0.39 & 103 & 207 \\
\hline R-ny40-1.5 & 1.5 & 40 & 0.39 & 103 & 182 \\
\hline R-ny40-2 & 2 & 40 & 0.39 & 43 & 244 \\
\hline R-PET30-1 & 1 & 30 & 0.7 & 43 & 219 \\
\hline R-PET30-1.5 & 1.5 & 30 & 0.7 & 57 & 229 \\
\hline R-PET40-1 & 1 & 40 & 0.7 & 57 & 196 \\
\hline R-PET40-1.5 & 1.5 & 40 & 0.7 & 90 & 213 \\
\hline PVA18-1 & 1 & 18 & 0.2 & 90 & 169 \\
\hline PVA18-1.5 & 1.5 & 18 & 0.2 & 45 & 213 \\
\hline PVA30-1 & 1 & 30 & 0.66 & & 189 \\
\hline PVA30-1.5 & 1.5 & 30 & 0.66 & 45 & \\
\hline
\end{tabular}

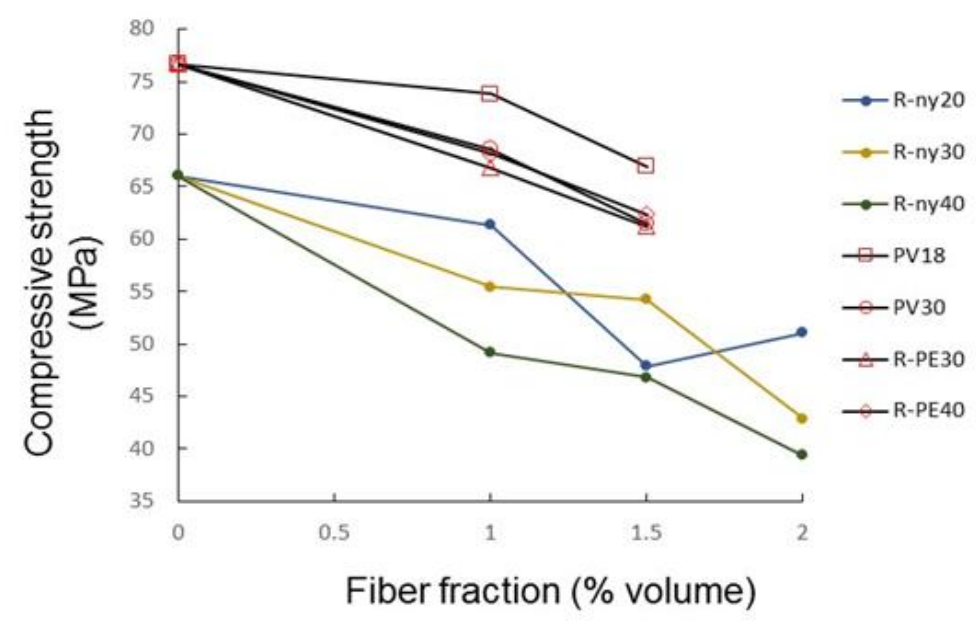

Figure. 2 Compressive strength of different fiber containing mortars 
Table 3. Results of compressive and flexural strengths at 28 days

\begin{tabular}{|c|c|c|c|c|c|c|c|c|c|}
\hline \multirow{2}{*}{ Types of specimen } & \multicolumn{3}{|c|}{ Compressive strength test } & \multicolumn{5}{c|}{ Flexural strength test } \\
\cline { 2 - 11 } & $\begin{array}{c}f_{c} \\
(\mathrm{MPa})\end{array}$ & $\begin{array}{c}S D \\
(\mathrm{MPa})\end{array}$ & $\begin{array}{c}\mathrm{CV} \\
\%\end{array}$ & $\begin{array}{c}\Delta f_{c} \\
\%\end{array}$ & $\begin{array}{c}P_{c r} \\
(\mathrm{kN})\end{array}$ & $\begin{array}{c}R \\
(\mathrm{MPa})\end{array}$ & $\begin{array}{c}S D \\
(\mathrm{MPa})\end{array}$ & $\begin{array}{c}C V \\
\%\end{array}$ & $\begin{array}{c}\Delta R \\
\%\end{array}$ \\
\hline UR1 & 66.05 & 3.25 & 10.61 & - & 2.00 & 5.63 & - & - & - \\
\hline R-ny20-1 & 61.32 & 4.81 & 7.85 & -7.16 & 2.83 & 7.97 & 0.24 & 8.31 & 41.68 \\
\hline R-ny20-1.5 & 47.87 & 2.56 & 5.36 & -27.52 & 2.17 & 6.09 & 0.23 & 10.78 & 8.25 \\
\hline R-ny20-2 & 51.04 & 4.23 & 8.29 & -22.72 & 2.17 & 6.09 & 0 & 0 & 8.35 \\
\hline R-ny30-1 & 55.46 & 2.13 & 3.84 & -16.04 & 2.29 & 6.44 & 0.29 & 12.87 & 14.58 \\
\hline R-ny30-1.5 & 54.23 & 3.13 & 5.77 & -17.90 & 2.37 & 6.68 & 0.06 & 2.59 & 18.68 \\
\hline R-ny30-2 & 42.88 & 2.63 & 6.12 & -35.07 & 2.42 & 6.80 & 0.35 & 14.63 & 20.85 \\
\hline R-ny40-1 & 49.18 & 7.12 & 14.47 & -25.54 & 2.34 & 6.57 & 0.12 & 5.15 & 16.75 \\
\hline R-ny40-1.5 & 46.80 & 8.62 & 18.42 & -29.15 & 2.13 & 5.98 & 0.18 & 8.32 & 6.25 \\
\hline R-ny40-2 & 39.40 & 3.40 & 8.63 & -40.34 & 2.38 & 6.68 & 0.29 & 12.39 & 18.75 \\
\hline UR2 & 70.83 & 10.21 & 14.42 & - & 1.71 & 4.81 & 0.06 & 3.31 & - \\
\hline R-PET30-1 & 66.82 & 1.62 & 2.42 & -5.67 & 2.21 & 6.21 & 0.06 & 2.66 & 29.15 \\
\hline R-PET30-1.5 & 61.24 & 4.56 & 7.44 & -13.54 & 2.13 & 5.98 & 0.47 & 19.52 & 24.27 \\
\hline R-PET40-1 & 68.13 & 3.43 & 5.03 & -3.81 & 2.13 & 5.98 & 0.53 & 24.96 & 24.27 \\
\hline R-PET40-1.5 & 62.37 & 7.34 & 11.77 & -11.94 & 1.96 & 5.50 & 0.53 & 27.00 & 14.42 \\
\hline PVA18-1 & 73.86 & 7.92 & 10.73 & 4.28 & 2.25 & 6.33 & - & - & 31.58 \\
\hline PVA18-1.5 & 66.95 & 5.25 & 7.84 & -5.48 & 2.38 & 6.68 & 0.06 & 2.50 & 38.89 \\
\hline PVA30-1 & 68.55 & 6.57 & 9.58 & -3.22 & 2.25 & 6.33 & - & - & 31.58 \\
\hline PVA30-1.5 & 61.49 & 2.87 & 4.66 & -13.19 & 2.08 & 5.86 & 0.24 & 11.30 & 21.84 \\
\hline
\end{tabular}

Note: There are two reference specimens that are UR1 and UR2, because the specimens were cast at difference batches.

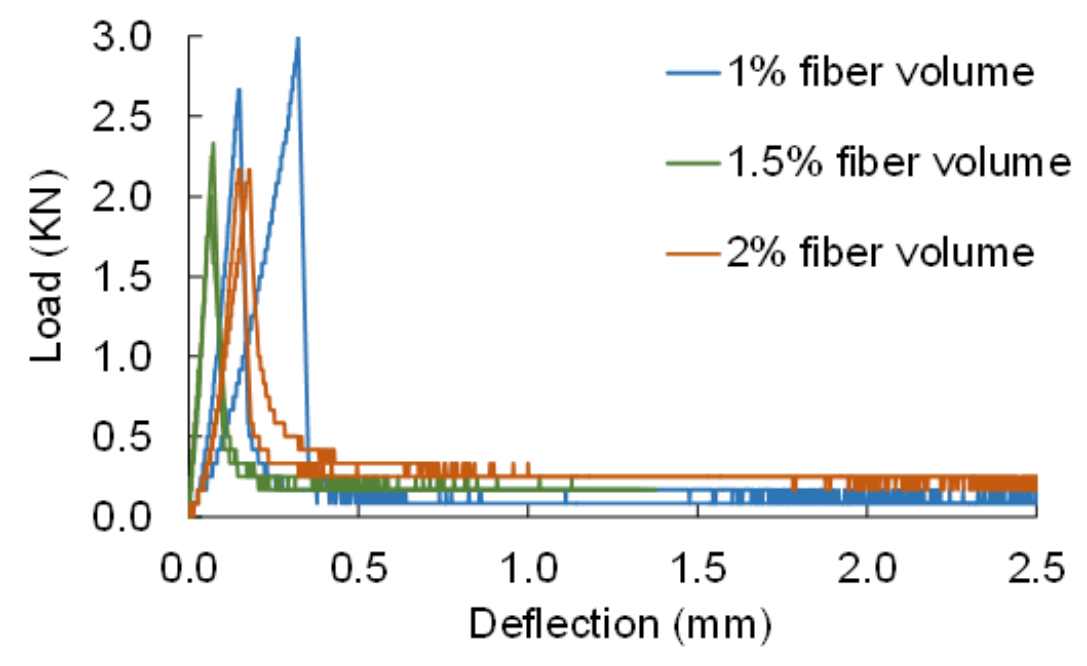

Figure 3. Load-deflection curves of mortar specimens reinforced with $20 \mathrm{~mm}$ R-nvlon fiber 


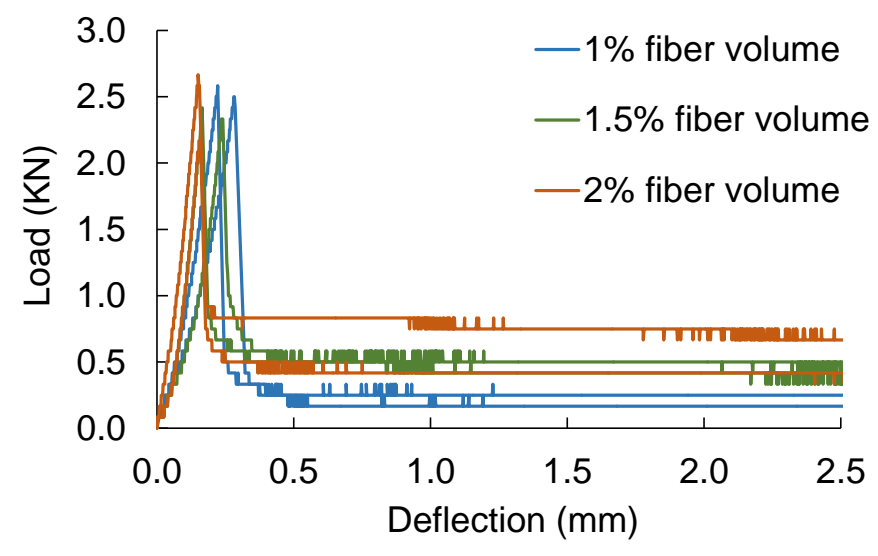

Figure 4. Load-deflection curves of mortar specimens reinforced with $30 \mathrm{~mm}$ R-nylon fiber

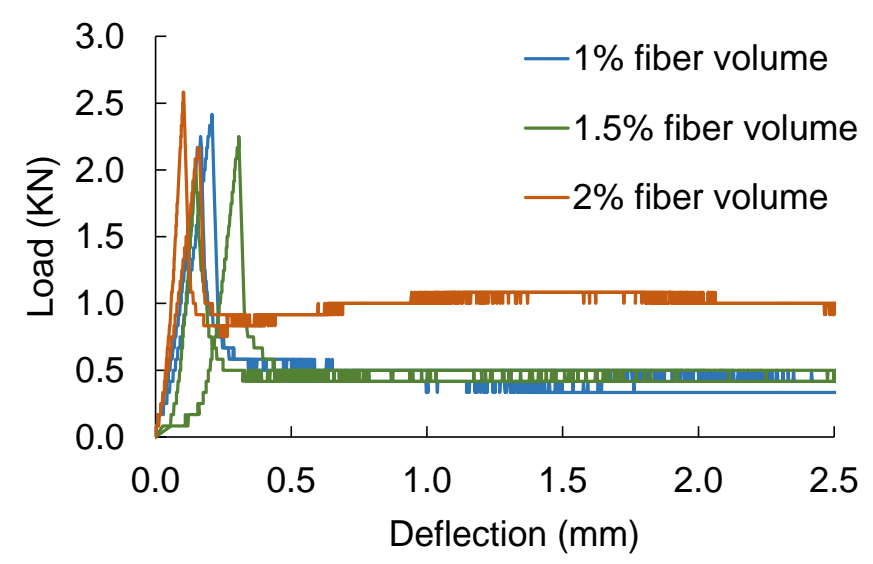

Figure 5. Load-deflection curves of mortar specimens reinforced with $\mathbf{4 0} \mathbf{~ m m} \mathbf{R}$-nylon fiber

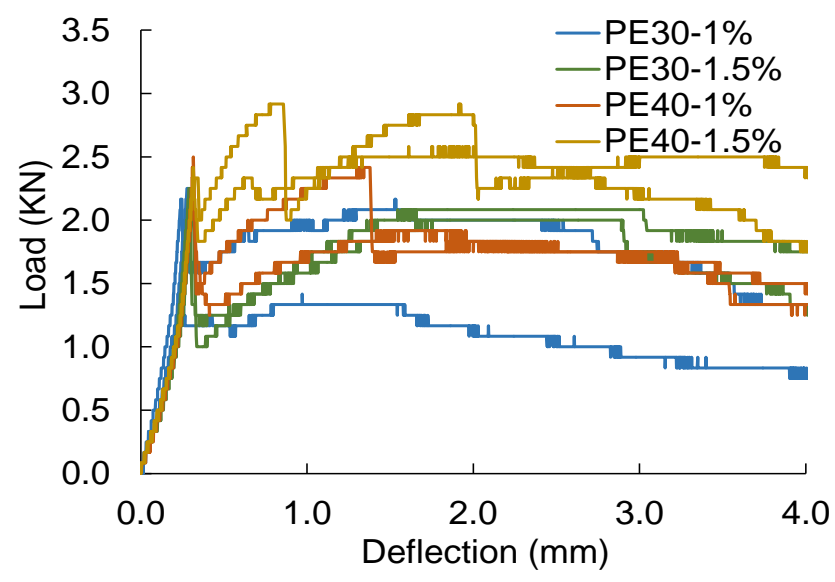

Figure 6. Load-deflection curves of mortar specimens reinforced with R-PET fibers 


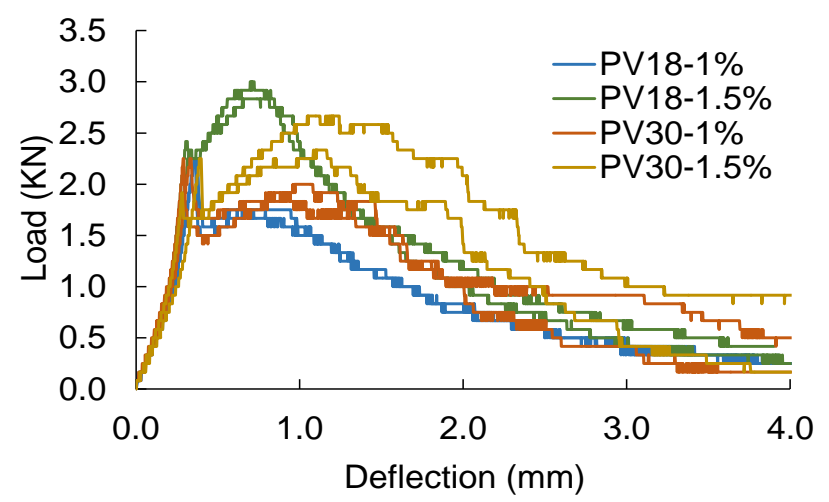

Figure 7. Load-deflection curves of mortar specimens reinforced with PVA fibers
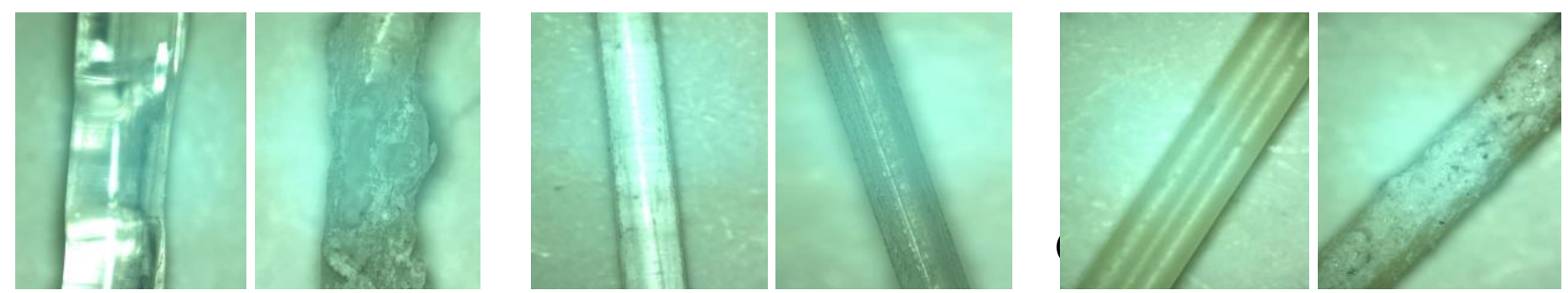

Figure 8. Surfaces of fibers before and after flexural test. (a) R-PET fiber, (b) R-nylon fiber, and (c) PVA fiber

From Figs. 3 to 7, the R-nylon fibers reinforced mortars show more relevant drop of the load after first cracking compare with PVA and R-PET fibers reinforced mortars. The second rising portion of the loaddeflection curve of PVA and PET fibers, prior to the second peak load, corresponded to a bond slip hardening effect. This phenomenon is very beneficial as long as the fiber tensile strength is not exceeded. The main reason why R-PET fibers are superior in post peak compare with other types of fiber may be concerned with the geometrical shape. The R-PET fibers were used in this study had an embossed surfaced that significantly increased bond between fiber and mortar. Kim et al. [2008] carried out an investigation focusing on the effects of the geometry of R-PET fibers on mechanical bond with cement based. In the mechanical bond test, the embossed fiber had hugely superior performance to the other types (straight and crimped). In case of PVA fibers, according to strong chemical bond between fibers and the hydrated cement matrix, this lead to fiber ruptured rather than pullout in the cement matrix [Nematollahi et al. 2015; Jewell et al. 2015]. When the specimens were subjected to bending load, PVA fibers tended to rupture before the bond between fibers and matrix break, this caused the post peak load of PVA fibers lower than R-PET fibers. Redon et al. [2001] conducted pull out test, two types of PVA fiber were investigated that were small diameter $(0.044 \mathrm{~mm})$ and large diameter $(0.700 \mathrm{~mm})$. They found that the small fibers ruptured before the full pullout length, while most of the large fibers were fully pulled out. Moreover, the surface of large fibers embedded in mortar were observed narrower than the original according to abrasion damage. In this study, the R-nylon, R-PET and PVA fibers surfaces were examined after bending test to analyze the frictional resistant force. As shown in figure 8 (a), the R-nylon fibers has no significant change in scratching, compare with the R-PET fibers. The surface of R-PET fibers were scratched (figure 8 (b)), the bond was strengthened by reason of mechanical anchorage effect in embossed area. In case of PVA fibers, there was some amount of cement matrix on the surface, due to strong chemical bond between fiber and matrix (Fig $8(\mathrm{c}))$. 


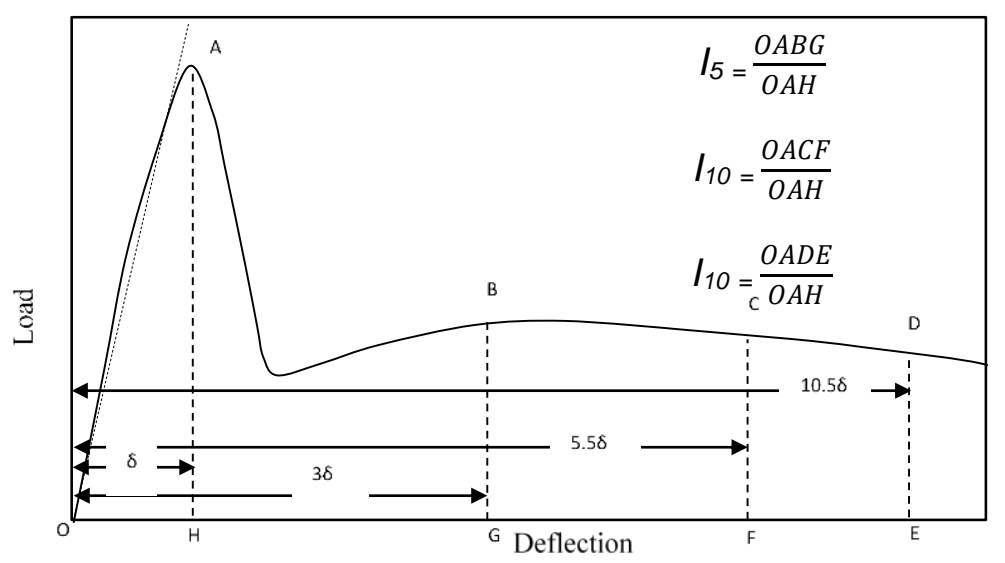

Figure 9. Toughness definition

Table 4. Toughness indices and residual strength factors at 28 days

\begin{tabular}{|c|c|c|c|c|c|}
\hline \multirow{2}{*}{ Types of specimen } & \multicolumn{3}{|c|}{ Toughness index } & \multicolumn{2}{c|}{ Residual strength factor } \\
\cline { 2 - 6 } & $I_{5}$ & $I_{10}$ & $I_{20}$ & $R_{5,10}$ & $R_{10,20}$ \\
\hline R-ny20-1 & 1.7 & 2.0 & 2.4 & 6.0 & 4.2 \\
\hline R-ny20-1.5 & 2.1 & 2.6 & 3.4 & 9.9 & 8.5 \\
\hline R-ny20-2 & 1.9 & 3.0 & 4.6 & 21.9 & 15.4 \\
\hline R-ny30-1 & 1.9 & 2.6 & 3.8 & 13.3 & 12.5 \\
\hline R-ny30-1.5 & 2.6 & 4.1 & 6.9 & 29.6 & 27.9 \\
\hline R-ny30-2 & 2.4 & 3.8 & 6.1 & 26.6 & 23.6 \\
\hline R-ny40-1 & 2.2 & 3.5 & 5.3 & 25.9 & 17.9 \\
\hline R-ny40-1.5 & 3.0 & 5.0 & 9.1 & 40.6 & 40.8 \\
\hline R-ny40-2 & 3.0 & 5.0 & 10.0 & 41.7 & 50.0 \\
\hline R-PET30-1 & 4.5 & 9.7 & 18.7 & 103.7 & 89.6 \\
\hline R-PET30-1.5 & 4.6 & 10.3 & 23.1 & 115.4 & 127.3 \\
\hline R-PET40-1 & 5.1 & 10.9 & 215 & 114.9 & 106.1 \\
\hline R-PET40-1.5 & 6.0 & 13.0 & 23.4 & 138.8 & 104.3 \\
\hline PVA18-1 & 4.6 & 7.6 & 11.3 & 59.6 & 37.1 \\
\hline PVA18-1.5 & 5.9 & 10.6 & 13.4 & 95.3 & 27.6 \\
\hline PVA30-1 & 5.1 & 7.8 & 12.4 & 53.8 & 45.7 \\
\hline PVA30-1.5 & 6.2 & 13.3 & 20.5 & 142.1 & 71.7 \\
\hline
\end{tabular}

\section{Effect of fiber content and fiber length on toughness}

According to ASTM C 1018, Toughness indices $I_{5}, I_{10}$ and $I_{20}$ are obtained by dividing the energy absorbed to a certain multi of first cracking deflection 3.0, 5.5 and 10.5 respectively, by the energy absorbed up to the first crack, as shown in figure 9. Toughness indices and residual strength factors are presented in Table 4. The results came as no surprise that addition of fibers into mortar appeared to have remarkable improvement on toughness property, especially when fiber fraction and aspect ratio increased. However, PVA fibers exhibited opposite results; that is, the lower aspect ratio fiber performed higher toughness and residual strength factors. Similar to the post peak behavior, the toughness property is also dependent on fiber characteristics, such as geometrical shape, tensile strength and Young's modulus as well as interfacial bonding strength between fiber and matrix. On comparing all types of fibers by similar aspect ratio, the highest toughness property and residual strength which are respectively as follows: R-PET, PVA and Rnylon. 


\section{CONCLUSION}

The effectiveness of three types of fiber were examined. The compressive and flexural tests were carried out to quantify compressive strength, modulus of rupture, post peak load, toughness indices and residual strength factors.

As evidence from this study, the effectiveness of R-nylon fiber reinforced mortar indicated the following:

- It was made clear that the R-nylon fiber has potential to use in mortar as an additive to improve its structural capacity.

- Addition of R-nylon fibers in to mortar resulted in 7-40\% reduction in compressive strength as the volume fraction and aspect ratio of fiber increased.

- R-nylon fibers from waste fishing net improved modulus of rupture (first crack strength) up to $41.7 \%$. The fiber reinforced mortars transformed a brittle fracture into more ductility.

- The post peak load, toughness indices and residual strength factors increased as increased in the amount and aspect ratio of R-nylon fiber.

On comparing all types of fiber in this study, the results can be concluded that:

- All types of fiber in this study reduced workability as compared with the same mortar without fiber. However, PVA fibers reduced more workability, compared with other types of fiber at same volume fraction.

- Post peak load, toughness and residual strength factors differed significantly according to fiber characteristics such as geometrical shape, tensile strength and modulus elasticity as well as bond between fiber and cementitious matrix. As evidenced by the flexural test, R-nylon fibers reinforced mortars had a significant lower post peak load than the mortars reinforced by R-PET and PVA fibers. In this study, R-PET fibers had an embossed surface that effectively improved bond between mortar and fiber. Despite strong chemical bond to the matrix of PVA fibers, the fibers tend to rupture instead of pull out in mortar. This caused PVA fibers exhibited lower post peak load than R-PET fibers when deflection increased. However, R-nylon fibers had superior first crack improvement to R-PET and PVA fibers.

- Addition of fibers in mortar resulted in reduction of compressive strength, especially, when low modulus fibers such as R-nylon fibers was mixed.

It has to be remarked, however, that R-nylon fiber reinforced mortar analyzed in this study proved to be beneficial in terms of first crack strength and material toughness as virgin fiber. Although, a higher fiber fraction may be required to match the performance.

The use of recycled fibers is beneficial in term of environmental effect, especially, R-nylon fibers reinforced mortar were examined in this study does not require any energy consumption process, while R-PET go through all cycles of industrial fibers manufacture. Moreover the use of recycled fibers consequently reduce product cost. In case of R-nylon fiber, the authors look forward to considering an admixture to increase fiber-matrix bond strength.

\section{REFERENCES}

ASTM C 39. "Standard test method for compressive strength of cylindrical compressive strength." ASTM International, West ConShohocken, PA, 5 pages. 
ASTM C 78. "Standard test method for flexural strength of concrete (Using simple beam with third point loading)." ASTM International, West ConShohocken, PA, 3 pages.

ASTM C 1018. "Standard test method for flexural toughness and first crack strength of fiber reinforced concrete." ASTM International, West ConShohocken, $P A, 8$ pages.

Fraternali, F., Farina, I., Polzone C., Pagliuca, E. and Feo, L. (2013). "On the use of R-PET strips for reinforcement of cement mortars." Composites B. 46, 207-210.

Habib, A., Begum, R. and Alam, M. M. (2013). "Mechanical properties of synthetic fibers reinforced mortars." Internal Journal of Scientific and Engineering Research, 4(4), 923-927.

Hu, W., Yang, X., Zhou, J., Xing, H. and Xiang, J. (2013). "Experimental research on the mechanical properties of PVA fiber reinforced concrete." Research Journal of Applied Science, Engineering and Technology, 5(18), 4563-4567.

Jewell, R. B., Mahboub, K. C., Robl, T. L. and Bathke, A. C. (2015). "Interfacial bond between reinforcing fibers and calcium sulfoaluminate cements: fiber pullout characteristics." ACI Materials Journal, 112(1), 38-47.

Karahan, O. and Atis, C. D. (2011). "The durability properties of polypropylene fiber reinforced fly ash concrete." Materials and Design, 32(2), 1044-1049.

Kim, J. H. J., Park, C. G., Lee, S. W., Lee, S. W. and Won, J. P. (2008). "Effects of the geometry of recycled PET fiber reinforcement on shrinkage cracking of cement-based composites." Composites B, 39, 442450.

Nematollahi, B., Sanjaya, J. and Ahmed Shaikh, F. U. (2015). "Tensile strain hardening behavior of PVA fiber-reinforced engineered geopolymer composite." Journal of Materials in Civil Engineering, ASCE, 27(10). Accessed January 6, 2015. doi: 1943-5533.0001242.

Ochi, T., Okubo, S. and Fukui, K. (2007). "Development of recycled PET fiber and its application as concrete-reinforcing fiber." Cement and Concrete Composites, 29, 448-455.

One Green Planet. <http://www.onegreenplanet.org> (Accessed Mar. 4, 2015).

Ozger, O. B., Girardi, F., Giannuzzi, G. M., Salomoni, V. A., Majorana, C. E., Fambri, L., Baldassino, N. and Maggio, R. D. (2013). "Effect of nylon fibers on mechanical and thermal properties of hardened concrete for energy storage systems.” Materials and Design, 51, 989-997.

Pereira de Oliveira, L. A. and Castro-Gomes, J. P. (2011). "Physical and mechanical behavior of recycled PET fibre reinforced mortar." Construction and Building Materials, 25, 1712-1717.

Redon, C. and Li, V. C. (2001). "Measuring and modifying interface properties of PVA fibers in ECC matrix." Journal of Materials in Civil Engineering, ASCE, 13(6), 399-406.

Silva, D. A., Betioli, A. M., Gleize, P. J. P., Roman, H. R., Gomez, L. A. and Ribeiro, J. L. D. (2005). "Degradation of recycled PET fibers in Portland cement-based materials." Cement and Concrete Research, 35(8), 1741-1746.

Song, P. S., Hwang, S. and Sheu, B. C. (2005). "Strength properties of nylon and polypropylene-fiberreinforced concretes." Cement and Concrete Research, 35(8), 1546-1550.

Spadea, S., Farina, I., Carrafiello, A. and Fraternali, F. (2015). "Recycled nylon fibers as cement mortar reinforcement." Construction and Building Material, 80, 200-209.

Wang, Y., Wu, H. C. and Li, V. C. (2000). "Concrete reinforcement with recycled fibers." Journal of Materials in Civil Engineering, 12(4), 314-319. 